\title{
Covid-19, Health Care in Ghana and the Fundamental Laws of Medical Science
}

\section{Ayim-Aboagye D*}

Department of Human Development and Psychology, Regent University College of Science and Technology, Ghana

*Corresponding author: Desmond Ayim-Aboagye, Department of Human Development and Psychology, Regent University College of Science and Technology, Ghana, Tel: +23302939900/+233243798102; Email: desmond.ayim-aboagye@regent.edu.gh

\section{Mini Review}

Volume 4 Issue 6

Received Date: December 02, 2021

Published Date: December 09, 2021

DOI: $10.23880 /$ jqhe-16000251

\section{Abstract}

The purpose of this article is to provide an overview of available research concerning covid-19 in Ghana. It presents challenges, measures from the health care delivery sector in the public health facilities. The article draws some strength from the fundamental laws of medicine as they aid to prepare the scientists in their combat against the novel Covid-19, its variants such as Delta and Omicron. Though the government has suffered economically from lockdowns and social interventions, its resilience efforts have been acclaimed to be successful and have to be emulated by other countries. The health care workers in Ghana's dissatisfaction with their jobs in these periods have not sidelined government efforts to lead and care for its citizens amid a pandemic.

Keywords: Healthcare; Economic Costs; Fundamental Laws of Medicine; Covid-19; Public Health; Health Provider; Patient; Vaccines

\section{Introduction}

Transmissions of diseases in the twenty-second century and onwards have not been easy and possible because of the increasing technologies already developed in the modern world. Though these technologies are available and highly efficient, we still depend on human efforts to halt the spread of highly infectious diseases; and this is because certain wellknown principles have been laid down by experts as guiding our efforts to obey the fundamental laws of medical science. This constant reminding shows that human efforts are as important ingredients to curb disease transmission just as the efficient technologies we have developed in this modern world are capable.

\section{The Objective of the Study}

The objective of this article is to analyze some published works on Covid-19 experience in Ghana. The review will also take into consideration the importance of the laws of medical science in support of the development of vaccines and the different strategies adopted to deal with the pandemic. The thesis is that Ghana did stupendously well to cater for its citizens, and though it suffered economically because of its numerous social interventions and lockdowns introduced, they barely affected the good morale the government had concerning the caring of its citizens at home and abroad.

\section{Methodology}

This work would consider the numerous data used, whether they employed interviews or surveys to accomplish their aims. The limitation of this article is that it does not employ any major new data apart from the short new data on the covid-19 variants such as Delta and the Omicron. The latter is now so much of its information gathered are narratives and do not lend itself to deep statistical analysis. The bulk of the work's data concentrate on secondary sources 
and these are competently presented in a table.

\section{Health Care and the Fundamental Laws of Medicine}

The fundamental laws of medical science state that 1 . "No disorder is without a symptom; vice versa, no symptom is without a disorder. 2. "Disease can be transmitted from one individual to one another if it is adjudged to be an infectious disease in the first place." 3. "The disease cannot be diagnosed by the patient unless there are within his presence competent experts who can advise the necessary steps to deal with and treat the disease." [1]

The alternative statements of the medical laws are 1 . If one diagnoses a patient as possessing a specific disorder, then there is a corresponding symptom(s) on which the practitioner has based his competent decisions/predictions. [If an individual $\mathrm{Q}$ is diagnosed as having a disorder $\mathrm{D}$, then there is a corresponding symptom $\mathrm{C}$ which lurks behind $\mathrm{D}$; then $Q_{\partial}=C \cong D$, and the vice versa is also true $Q_{\partial}=D \cong C$. Where ${ }_{a}$ represents the condition of Q.] 2. In cases where a disorder is judged to be an infectious disease or violent personality disorder, there is a greater likelihood that a patient can transmit this disorder to other individuals irrespective of who comes into contact with him. [Suppose that $\mathrm{Q}_{ə}$ were to be the distressed patient in a zero-point condition $(\mathrm{Zc})$ who is distressed, petrified, and disequilibrium, then the following (could result) patients can contract the illness from $\left\{Q_{\partial} \rightarrow\right.$ $\left.\left.\mathrm{Q}_{\partial} 1 \rightarrow \mathrm{Q}_{\partial} 2 \rightarrow \mathrm{Q}_{\partial} 3 \rightarrow \ldots \mathrm{Q}_{\partial} \mathrm{N}\right\}\right]$. The formula then becomes $\mathrm{Zc}$ $=Q_{\partial} \rightarrow Q_{\partial} 1 \rightarrow Q_{\partial} 2 \rightarrow Q_{\partial} 3 \rightarrow \ldots Q_{\partial}$ N. 3. A diagnostic procedure involving a disorder is not handled in isolation by a patient; it is attended to and steered by a competent practitioner who confronts a distressed patient that has voluntarily sought help. [Let $\mathrm{Q}$ be in the zero-point condition $(\mathrm{Zc})$ of illness $Q_{\partial}$ that is distressed, petrified, and disequilibrium. For every zero-point condition $\mathrm{Q}_{\partial}<\mathrm{S}>\mathrm{Q}$. Then, the following inequalities hold at any zero-point condition: $Z c c=Q_{\partial}\langle S\rangle$ $\mathrm{Q}$. This means $\mathrm{Q}_{\partial}$ is subservient to $\mathrm{S}$, the practitioner that is more knowledgeable than $Q$ in the encompassing powerful context of medical diagnosis] [2-6].

When one observes the commencement of the Covid-19 pandemic, which recently originated in the Far East and spread quickly to the Western World and Africa, and other parts of the world, it immediately informs one that these laws have been the guiding principles to lead the scientists concerning the development of different strategies to deal with the spread and the eventual development of the vaccines.

First, the fundamental laws of medical science provided the scientists the idea to look at the relationship between the symptoms and the disorder relation/perspective to investigate and develop the correct vaccine. Different researches had already taken place regarding previous Covid related cases. The knowledge of the disorder-symptom relation helped these renowned men to develop the vaccines, which occurred in the United Kingdom, China, Russia, and the USA.

Again, the second law of medical science talks about disease transmission that made these experts think about the vaccine to furnish the immune system through the development of antibodies. They discovered more avenues to stop the spread between individuals, patients, and nonpatients. The science concerning the transmission from the zero point condition $(\mathrm{Zc})$ by patient zero $\left(\mathrm{Zc}=\mathrm{Q}_{\partial} 0 \ldots \mathrm{Q}_{\curvearrowright} \mathrm{N}\right.$. $)$ educated the scientists who made the vaccine development a matter of urgency. These gentlemen had this information at the forefront of their minds. They possessed knowledge of the previous cases of viral infection and all manner of causes. That led them to the right decisions on how to come out with these right medicines. Think about the immediate spread of the disease into the different continents overnight. How they had them on their considerations in their minds, that is, to hit at the appropriate vaccine that could offer men the equilibrium-point condition $(\mathrm{Ec})$, which is synonymous to absolute wellness.

Third, concerning the presence of scientists to help with the competent diagnoses and the given of the vaccine, we think of the third fundamental law of medicine. The vaccines must be given to patients and non-patients alike to have confidence in the vaccines. The presence of a competent practitioner is inevitable. Fundamental theorems, furthermore, establish the existence of common grounds upon which all medical diagnoses rest among a collection of abnormalities defined on certain arranged disorders that are subject to diagnostic procedures. The laws are relevant both because of their interdependent theoretical significance and because other results can be deduced from them that can be corollaries.

\section{Vaccine Development, Political-Economic Context and the Pandemic}

What Covid-19 response has taught the community of medical scholars is about the fact that the fundamental laws of medical science are necessary at the onset of any pandemic which the virus caused. The law, among other things, has given the medical community the confidence we have in vaccines. Vaccine confidence is the belief that vaccination and the providers, private sector, and political actors behind it serve the public's best health interests like 'hesitancy' and is highly variable and rooted in a political-economic context. These affect the populations' trust in vaccines. 
The Covid-19 vaccine, like other vaccines, works by training own bodies to develop antibodies to fight against the virus that causes Covid-19 to prevent future illness.

Despite all the news about the vaccine's protection, other forms of protection are online. Thus there is a onemeter distance between others that people should observe. They should always wear masks. They should prioritize the cleaning of their hands with sanitizers. They should cover their noses with their face masks and leave the already-used face masks in the dustbin. They should avoid face masks that have valves. And above all, both well and non-well individuals should go for the vaccines to curtail the spread. They should consider these simple health care interventions from the different perspectives of points of view, where the patient, the health care provider, and the society as a whole must be encouraged to participate in [7].

Vaccine development reminds us of the different ranging methods which come to play in the field of political-economic context. These methods are cost-effectiveness, cost-utility, cost-benefit, cost of illness, and the budget impact, which form the basis of modern research. The political actors must take these methods to help economic analyses and health care interventions. These, which consist of the public policy, must be seriously addressed as they have more impact on family planning services and insurance costs.

In the world around, countries have resorted to social distancing, travel restrictions, and economic lockdowns to reduce transmission of COVID-19. The socioeconomic costs of these strict measures have been exceedingly high, especially in sub-Saharan Africa, where many citizens live hand-to-mouth and lack social safety nets. Social Accounting Matrix multiplier model results have shown that Ghana's urban lockdown, although in force for only three weeks in April 2020, had likely caused GDP to fall by $27.9 \%$ during that period, while an additional 3.8 million Ghanaians temporarily had become poor. These have presented a sad situation. Compared to the government's revised GDP growth rate of $1.5 \%$ for 2020 , the model had predicted a contraction of 0.6 to $6.3 \%$ for 2020 , depending on the recovery speed. The US $\$ 200$ million budgeted for Ghana's Coronavirus Alleviation Program will close only a small part of the estimated US $\$ 2.3$ billion GDP gap between the fast recovery scenario and the government's revised GDP trajectory [8].

\section{Covid-19, the Pandemic and the Case of Ghana}

When the first vaccines by Astra Zeneca arrived in Ghana from the United Kingdom, many people were glad beyond measure to its arrival. The aged people got the first shots, followed by those at the risk zone. Ghana, unlike some countries in Southern Africa, had many people taking the vaccine shots. The vaccine got finished quickly and, the government had to order the next consignment for the second shot. Indeed, many people came to take part but as assured, they gave priority to those who were working with patients in the hospitals.

When the second consignment came, experience tells us that many people who had not had their first shot were eager to use the opportunity to do that. But time and again, experts cautioned the danger of doing that. A story goes that many people come forward pretending to be researchers who had to travel abroad for a conference and, therefore, they should have a preference to have the first shot. None of these attempts to sideline the principles guiding the Covid-19 vaccination yielded success.

Currently, Ghana is waiting for another consignment that they will use to give shots to the general population apart from the recent shipment from Johnson and Johnson. They will inject these to administer to those who had not been serious at first when the first consignment came. This time there will be no priority groups, as all will be encouraged to have access. Apart from these consignments, donations have poured in from different countries and organizations abroad and the data below show that a great deal of progress has been achieved by Ghana in its quest to vaccinate its 30 million populations against Covid-19.

But the review will not be worthwhile if we do not mention some of the challenges that the nation faced during these difficult moments. There were, in fact, challenges which consist of the following: 1) problems with case management practices; 2) challenges with hospital beds Ghana had a sign of critical care beds that were in shortages; 3 ) there were shortages of antiviral drugs; 4) oxygen ventilators were in great need; 5) Vaccination procurement: the right market price was not given to Ghana. This controversy landed the Health minister in trouble because some middlemen wanted to dupe the country millions of dollars by offering exorbitant prices, and 6) high-risk population because of poverty and inability to purchase masks for protection [9].

One could assert Ghana's effective track and trace system, as well as lockdown and other measures, had helped limit mortality of only 85 recorded deaths by 23rd June 2020, according to one researcher [10]. Scientists from three facilities of the University of Ghana had also successfully sequenced the genomes of COVID-19 from 15 confirmed cases and, The Food and Drugs Authority in Ghana had also helped address shortages by fast-tracking certification of hand sanitizers and local production of 3.6 million standardized personal protective equipment. There was the development of prototypes of locally-manufactured mechanical ventilators to meet the local needs at intensive 
care units. Thanks to so many scientific institutions that had specialized in the innovation of these new ideas and technologies. Most people resorted to changing diets and used supplements to boost their immune systems. Although these initial results were encouraging, further research will be needed to comprehend the dynamics of COVID-19 in Ghana and provide more learned experiences.

\section{Infection Rate: Current Statistical Data}

Ghana has recorded 131000 cases of Covid-19 infections. Sadly 1,209 have died. This information is in Table 1 below. The total doses given are 3, 493 688. People fully vaccinated are 842225 .

\begin{tabular}{|c|c|c|c|c|c|c|}
\hline \multicolumn{2}{|c|}{ Statistics } \\
\hline Cases & Vaccines & Total cases & New case/day & $\begin{array}{c}\text { New cases last 60 } \\
\text { days }\end{array}$ & $\begin{array}{c}\text { Cases /One million } \\
\text { people }\end{array}$ & Death \\
\hline Location & & & & & & 33,717 \\
\hline Worldwide & & $262,181,360$ & 677,338 & & 4,324 & $1,207,585$ \\
\hline Ghana & & 130,920 & 0 & & & 1,209 \\
\hline
\end{tabular}

Table 1: Ghana and World Data on COVID-19 Cases.

- The number of cases reported for the most recent day of complete data within the last three days.

- About this data - Sources: Our World in Data, Johns Hopkins University

One recent work that provided a situational update on COVID-19 in Ghana reported Ghana as one of the countries that reported the most cases. The work saw some modifications occurring within the health system to curtail the outbreak and its potential impact on the delivery of antenatal care services. With the discovery of the Delta variant in Ghana, there was attention to preventing a third wave of infection and controlling and managing existing cases. They made efforts to procure vaccines, vaccinate special populations and sensitize the public on the implications of the vaccine. Amidst these activities, the study suggested some innovations and countermeasures safeguard primary healthcare services and potentially reinvest efforts towards achieving the sustainable development goal three within the context of maternal healthcare. They cited examples specific to developing countries, such as Ghana [11].

\section{Discussion and Concluding Remarks}

Certain things appear to be salient in this piece of work and, we must discuss them apart from the general conditions that prevailed in the Ghanaian context. The laws of medicine are vital because they guide the practitioners to deal with cause-effect structure, which are general principles enshrined in the scientific method. Generally, in every diagnosis, the fundamental laws are what the practitioner focuses on. They deal with symptom-disorder relationships, disorder-transmission relationships, and the practitioner-patient relationship. These are vital laws even in the development of vaccines and the different strategies adopted to deal with both patients and non-patients when they receive their vaccine shots. These laws had helped many renowned scientists like Hermann Koch to discover anthrax and TB, Alexander Fleming to invent penicillin, and Watson and Crick to discover the DNA double-helix structure. The laws continue to inspire others. They appear to support the continuous discoveries in new vaccines, antibiotics, antiviral drugs, and the unveiling of useful medicines in research.

Ghana has recorded some cases of the new Omicron COVID-19 variant. Before December 2021, according to the Director-General of the Ghana Health Service, Dr. Patrick Kumah Aboagye, they identified through the meticulous testing they did at Kotoka International Airport. These had come from other countries such as Nigeria and South Africa, where they had already recorded some cases. In the same month, Nigeria, for example, had confirmed some three covid cases of the new variant in the country. Ghana Health Service says the new variant has not yet been found in the Ghanaian communities. But this was before December month.

However, on the second day of December 2021, Ghana's foremost medical research institution announced confirmation of 34 cases of the Omicron variant in the country. In their revelation, Noguchi Memorial Institute for Medical Research (NMIMR) asserted that it had detected the virus in 34 out of the 120 samples collected from travelers arriving at the Kotoka International Airport between November 21 and 24, 2021. The positive cases comprise 28 percent of the total number tested, and these are the first imported cases in Ghana. The NMIMR added that "We are closely monitoring its spread in the local population. We encourage the general public to continue adhering to the COVID-19 prevention protocols" [12]. The Ministry of Health in Ghana has, therefore, declared December a month of mandatory vaccination for all residents against the pandemic. 


\section{References}

1. Ayim Aboagye D (2019) On the Existence of Fundamental Theorems of Medical Diagnoses and Practice. Journal of Health and Medical Sciences 2(3): 304-311.

2. Evans AS (1978) Causation and disease: a chronological journey. The Thomas Parran Lecture. American Journal of Epidemiology 108(4): 249-258.

3. Fredericks DN, Relman DA (1996) Sequence-based identification of microbial pathogens: a reconsideration of Koch's postulates. Clin Microbiol Rev 9(1): 18-33.

4. Koch $\mathrm{R}$ (1876) Investigations into bacteria: V. The etiology of anthrax, based on the ontogenesis of Bacillus anthracis. Cohns Beitrage zur Biologie der Pflanzen 2(2): 277-310.

5. Koch R (1893) About the instantaneous state of the bacteriological diagnosis of cholera. Zeitschrift für Hygiene und Infektionskrankheiten 14: 319-338.

6. Koch $\mathrm{R}$ (1876) Investigations into bacteria: V. The etiology of anthrax, based on the ontogenesis of Bacillus anthracis. Cohns Beitrage zur Biologie der Pflanzen 2(2):
277-310.

7. Agyeman E (2021) Face Mask Use among Commercial Drivers during the Covid-19 Pandemic in Accra, Ghana. Journal of Community Health 46: 1226-1235.

8. Amewu S (2021) The Economic Costs of Covid-19 in SubSaharan Africa: Insights from a Simulation Exercise for Ghana. The European Journal of Development Research 32: 1353-1378.

9. Nakkazi E (2021) How Covid-19 Affected Healthcare Workers in Ghana and Kenya. Nature Africa.

10. Afriyie, DK (2020) Covid-19 Pandemic in Resource-Poor Countries: Challenges, Experiences, and Opportunities in Ghana. Journal of Infection Developing Countries 14(8): 838-843.

11. Agbozo F, Jahn A (2021) Covid-19 in Ghana: Challenges and Countermeasures from Maternal Health Service Delivery in Public Health facilities. Reproductive Health BMC 18: 151.

12. Huaxia (2021) Ghana Records 34 Cases of Omicron Variant. Xinhuanet. 